\title{
Hydroalumination of Cyclopropane: A Transition State Study
}

\author{
SATYA PRAKASH SINGH* ${ }^{*}$ and POMPOZHI PROTASIS THANKACHAN
}

Department of Chemistry, Indian Institute of Technology Roorkee, Roorkee - 247667, India satyapiit@gmail.com

Received 20 November 2012 / Accepted 15 December 2012

\begin{abstract}
The hydroalumination of cyclopropane has been investigated using the B3LYP density functional method employing several split-valence basis sets. It is shown that the reaction proceeds via a four-centered transition state. Calculations at higher levels of theory were also performed at the geometries optimized at the B3LYP level, but only slight changes in the barriers were observed. Structural parameters for the transition state are also reported.
\end{abstract}

Keywords: Hydroalumination, Cyclopropane, Transition state, Propylalane

\section{Introduction}

Aluminium and boron belong to group III in the periodic table but there is large difference in their chemistry ${ }^{1-3}$. Only a few hydrides of aluminium are known along with monomer $\mathrm{AlH}_{3}$ and dimer $\mathrm{Al}_{2} \mathrm{H}_{6}$ while boron has a richer chemistry ${ }^{4,5}$ in the inorganic as well as organic chemistry. Hydrides of aluminium are good reducing agents and used as reducing agent for functional groups, hydroalumination of alkenes, alkynes, allylic rearrangement in organic chemistry ${ }^{6}$.

The addition of the Al-H bonds to the double or triple bonds of unsaturated organic compounds (hydroalumination) finds widespread application as a very powerful method for the reduction of specific substrates in organic synthesis ${ }^{7-15}$.

The addition of an alkene or alkyne into the Al-H bond of an alkyl aluminium hydride is a key first step in the route to the formation of a new carbon-hydrogen bond via hydroalumination. For further understand Bunden and Francl $^{16}$ used $a b$ initio molecular orbital methods to probe the reaction path for the addition of carbon-carbon multiple bonds into $\mathrm{Al}-\mathrm{H}$ bonds.

Several theoretical studies of the hydroalumination of ethylene and acetylene have appeared. It has been suggested that the reaction involves formation of a symmetric $\pi$-complex intermediate leading to the formation of addition product via a four-centered transition state. Experimental work by Egger supports these results ${ }^{17}$. The alternative $\pi$-complex transition state proposed by $\operatorname{Eisch}^{18}$; however, is inconsistent with both the theoretical studies and the experimental work of Egger $^{17}$. In 1981, Grophen and Haaland 
characterized the transition structure for the addition of acetylene into the $\mathrm{Al}-\mathrm{H}$ bond of alane ${ }^{19}$. One year later, they have reported the transition structure for the analogous addition reaction of $\mathrm{AlH}_{3}$ with ethylene ${ }^{20}$. Sakai described a push-pull two-stage mechanism for the analogous reaction of $\mathrm{AlH}_{3}$ with ethylene ${ }^{21}$. Sakai's charge analysis on hydroalumination of ethylene suggested initial $\mathrm{Al}-\mathrm{C}$ bond formation occurs which is found rapid than the breaking $\mathrm{Al}-\mathrm{H}$ and the making of $\mathrm{C}-\mathrm{H}$ bonds. Higashi et al. investigated the reverse reaction of $\mathrm{AlH}_{3}+\mathrm{C}_{2} \mathrm{H}_{4}$ in the contest of its application to chemical vapour deposition ${ }^{22}$. They have reported a four-centered alane-ethylene transition structure using a more sophisticated theoretical model although no substantial differences were found.

Houk et $a .^{23,24}$ and others ${ }^{25}$ have examined the reaction path for the analogous hydroboration reaction with a variety of substrates. The intermediates and transition structures found in these studies are consistent with those for the hydroalumination pathway described earlier. Qualitatively, the energetics of these pathways compare well with those from the simple hydroalumination reaction studied earlier. Schleyer and Hommes ${ }^{26}$ have examined the structure of the transition state for the reaction of dimethylborane and ethylene using correlated methods and suggest that the TS has a three-centered rather than fourcentered structure. Chey et al. ${ }^{27}$ have previously characterized the $\pi$-complex intermediates for hydroalumination of alkenes. In 1999 Bunden et $a l .{ }^{28}$ have studied the transition state for the carboalumination of alkene and alkynes at ab initio level of theory. They have shown that these reactions are essentially nucleophilic attacks by alkyl anions on substrate activated by lewis acid substituents.

Togni and Grutzmacher ${ }^{29}$ in 2001 have proposed metal-catalysed hydroalumination reactions of alkenes and alkynes and suggested that the catalytic hydroalumination of alkenes and alkynes is the potential tool for the functionalization of carbon-carbon multiple bonds. Among the different catalytic systems titanium (Ti), Zirconium (Zr) and Nickel (Ni) catalysts have found the widest application. Pankratyev et al. ${ }^{30}$ has recently carried out a DFT study on the mechanism of olefin hydroalumination by $\mathrm{XAlBu}_{2}{ }^{i}$ in the presence of $\mathrm{Cp}_{2} \mathrm{ZrCl}_{2}$ catalyst for the mechanism of intermediate formation.

In this paper, we report our studies on the hydroalumination of cyclopropane with alane. Unlike hydroboration of cyclopropane ${ }^{31}$ we found a four-centered transition state leading to the formation of $n$-propyl alane. A four-centered transition state occurs on the approach of $\mathrm{AlH}_{3}$ moiety along the plane of cyclopropane ring and proceeded by an intermediate complex.

\section{Computational methods}

All calculations have been performed on a PC running WINDOWS using the Gaussian $98^{32}$ suite of programs. The B3LYP hybrid density functional was used for calculation at DFT $^{33}$ level using several split-valence basis sets. The geometries of the reactants $\left(\mathrm{AlH}_{3}\right.$ and $\mathrm{C}_{3} \mathrm{H}_{6}$ ), transition state and the product were optimized at this level of theory using 6-31G**, 6-311++G**34-40, cc-pVDZ and AUG-cc-pVTZ ${ }^{41-45}$ basis sets. The nature of each stationary point was confirmed in each case by frequency calculations; all the minima were verified to have all positive frequencies and the transition state to have only one imaginary frequency. MP2 ${ }^{46-50}$ calculations were also performed using the chosen basis sets for comparison purposes. Single point (SP) calculations were also performed at the geometries optimized at the B3LYP/6-31G** level at the $\operatorname{CCSD}, \operatorname{CCSD}(\mathrm{T})^{27-31}$, QCISD, QCISD(T) $)^{51-55}$ and MP4D levels to see if any significant change in the energetics is observed. 


\section{Results and Discussion}

When aluminium approaches a $\mathrm{C}-\mathrm{C}$ bond of cyclopropane along a line perpendicular to the ring plane no stable intermediate is found. However a four-centered transition structure is obtained.

The geometry of the reactants $\left(\mathrm{AlH}_{3}\right.$ and $\left.\mathrm{C}_{3} \mathrm{H}_{6}\right)$ four-centered transition state optimized at B3LYP/6-31G** level is shown in Figure 1. The geometrical parameters for the optimized transition structure are listed in Table 1.

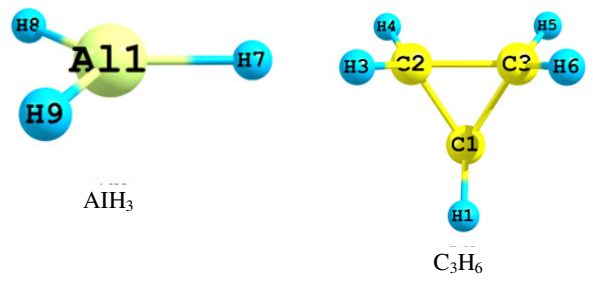

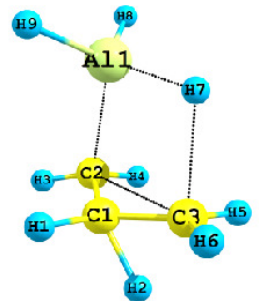

TS

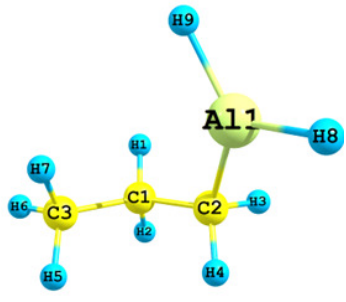

LM2

Figure 1. B3LYP/6-31G** optimized geometry of the reactants $\left(\mathrm{AlH}_{3}\right.$ and $\left.\mathrm{C}_{3} \mathrm{H}_{6}\right)$, four centered transition state (TS) and product

Table 1. Optimized structural parameters (bond lengths in $\AA$ and angles in degree) for the four-centered transition state (TS)

\begin{tabular}{ccccc}
\hline & $\mathrm{AlH}_{3}$ & $\mathrm{C}_{3} \mathrm{H}_{6}$ & $\mathrm{TS}$ & $\mathrm{LM}$ \\
\hline $\mathrm{R}(\mathrm{Al1} 1 \mathrm{H} 7)$ & 1.58689 & & 1.703 & 3.08400 \\
$\mathrm{R}(\mathrm{A} 11-\mathrm{H} 8)$ & 1.58665 & & 1.599 & 1.59252 \\
$\mathrm{R}(\mathrm{Al1}-\mathrm{H} 9)$ & 1.58709 & & 1.605 & 1.59269 \\
$\mathrm{R}(\mathrm{C} 1-\mathrm{C} 3)$ & & 1.50907 & 1.420 & 1.53195 \\
$\mathrm{R}(\mathrm{C} 2-\mathrm{C} 3)$ & & 1.50899 & 2.474 & 2.56261 \\
$\mathrm{R}(\mathrm{C} 1-\mathrm{C} 2)$ & & 1.50889 & 1.437 & 1.54117 \\
$\mathrm{R}(\mathrm{C} 1-\mathrm{H} 1)$ & & 1.08551 & 1.089 & 1.09784 \\
$\mathrm{R}(\mathrm{C} 1-\mathrm{H} 2)$ & & 1.08551 & 1.291 & 1.09908 \\
$\mathrm{R}(\mathrm{C} 2-\mathrm{H} 3)$ & & 1.08550 & 1.089 & 1.10315 \\
$\mathrm{R}(\mathrm{C} 2-\mathrm{H} 4)$ & & 1.08550 & 1.091 & 1.09998 \\
$\mathrm{R}(\mathrm{C} 3-\mathrm{H} 5)$ & & 1.08549 & 1.082 & 1.09623 \\
$\mathrm{R}(\mathrm{C} 3-\mathrm{H} 6)$ & & 1.08549 & 1.085 & 1.09494 \\
$\mathrm{R}(\mathrm{A} 11-\mathrm{C} 2)$ & & & 2.162 & 1.97427 \\
$\mathrm{R}(\mathrm{A} 11-\mathrm{C} 3)$ & & & 3.051 & 3.49260 \\
$\mathrm{R}(\mathrm{C} 3-\mathrm{H} 7)$ & & & 1.997 & 1.09828 \\
$\angle \mathrm{C} 1 \mathrm{C} 2 \mathrm{C} 3$ & & 60.006 & 29.8 & 33.387 \\
$\angle \mathrm{C} 2 \mathrm{C} 3 \mathrm{C} 1$ & & 59.994 & 30.2 & 33.615 \\
$\angle \mathrm{C} 3 \mathrm{C} 1 \mathrm{C} 2$ & & 60.000 & 119.8 & 112.998 \\
$\angle \mathrm{H} 7 \mathrm{Al1H} 9$ & 119.990 & & 107.7 & 76.386 \\
$\angle \mathrm{H} 8 \mathrm{~A} 11 \mathrm{H} 9$ & 119.981 & & 118.1 & 118.541 \\
$\angle \mathrm{H} 8 \mathrm{~A} 11 \mathrm{H} 7$ & 120.029 & & 117.2 & 135.799 \\
\hline
\end{tabular}

The C2-C3 distance in the transition state of $2.474 \AA$ is greater than the $\mathrm{C} 2-\mathrm{C} 3$ distance found in the four-centered transition state in which $\mathrm{AlH}_{3}$ moiety is oriented along the plane of cyclopropane ring by $0.309 \AA$. The forming C3-H7 and C2-Al1 bonds are of comparable 
length in both the transition states. The HOMO of the transition state is shown in Figure 2 enabling us to visualize the electron density distribution around the forming and breaking bonds.

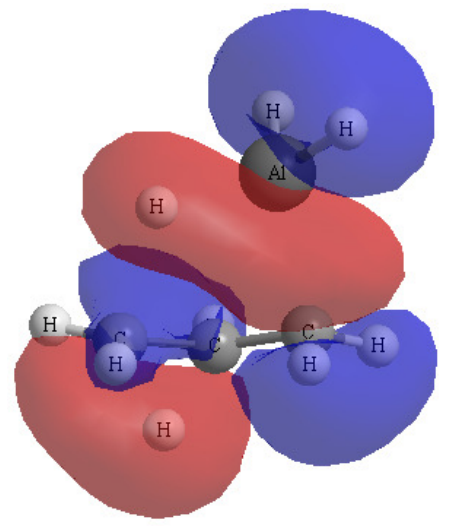

Figure 2. HOMO of the four-centered transition state (TS) for the hydroboration of cyclopropane at B3LYP/6-31G** level of calculation

The IRC plot computed from this four-centered transition state is shown in Figure 3 and shows the transition state moving downhill towards the reactants on one side and the product the other. Frequency calculation has been performed on the transition state confirms the existence of a single imaginary frequency $\left(1275 \mathrm{~cm}^{-1}\right)$.

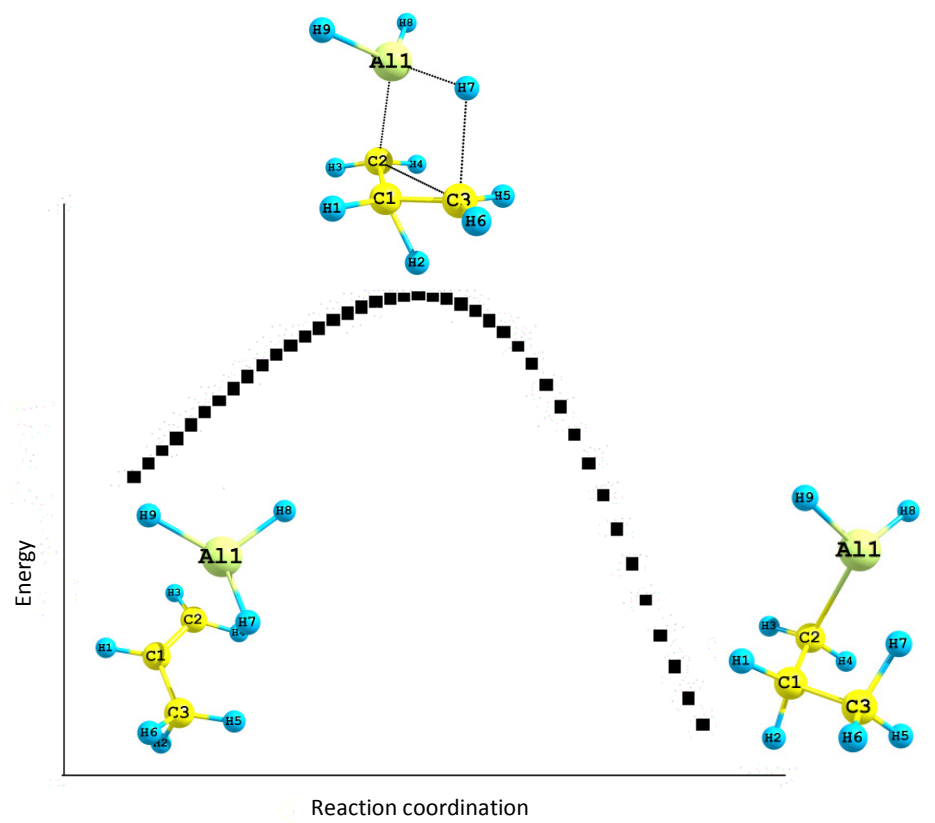

Figure 3. IRC plot for the four-centered transition state at the B3LYP/6-31G** level

Calculations at different levels and using different basis sets have been performed in this case also. The total energies (in Hartree) and the relative energies (in $\mathrm{kcal} / \mathrm{mol}$ ) for the reactants, transition state and product are listed below in Table 2 and Table 3 respectively. 
Table 2. Total energies (in Hartree) and relative energy (in $\mathrm{kcal} / \mathrm{mol}$ ) for the reactants, fourcentered transition state and product at different levels and basis sets

\begin{tabular}{lccc}
\hline \multicolumn{1}{c}{ Method } & $\mathrm{AlH}_{3}+\mathrm{C}_{3} \mathrm{H}_{6}$ & $\mathrm{TS}$ & $\mathrm{LM} 2$ \\
\hline B3LYP/6-31G** & -362.1110943 & -362.0469598 & -362.1672311 \\
B3LYP/cc-pVDZ & -362.1152736 & -362.0513688 & -362.1691517 \\
B3LYP/6-311++G** & -362.1600749 & -362.0950096 & -362.2144364 \\
B3LYP/AUG-cc-pVTZ & -362.1770811 & -362.1125874 & -362.2308314 \\
MP2/6-31G** & -361.1874839 & -361.1111888 & -361.2450056 \\
$\mathrm{MP} 2 / \mathrm{cc}-\mathrm{pVDZ}$ & -361.1998152 & -361.1280688 & -361.2566437 \\
${ }^{a} \mathrm{QCISD} / 6-31 \mathrm{G}^{* *}$ & -361.2437676 & -361.1669392 & -361.3010989 \\
${ }^{a} \mathrm{QCISD}(\mathrm{T}) / 6-31 \mathrm{G}^{* *}$ & -361.2587135 & -361.1861454 & -361.3164128 \\
${ }^{a} \mathrm{MP} 4 \mathrm{D} / 6-31 \mathrm{G}^{* *}$ & -361.2481001 & -361.1693367 & -361.3055561 \\
${ }^{a} \mathrm{CCSD} / 6-31 \mathrm{G}^{* *}$ & -361.2432854 & -361.1653982 & -361.3005232 \\
${ }^{a} \mathrm{CCSD}(\mathrm{T}) / 6-31 \mathrm{G}^{* *}$ & -361.2585268 & -361.1855883 & -361.3161846 \\
\hline
\end{tabular}

${ }^{a}$ Single point calculations on the B3LYP/6-31G** structures.

Table 3. Total energies (in Hartree) and relative energy (in $\mathrm{kcal} / \mathrm{mol}$ ) for the reactants, fourcentered transition state and product at different levels and basis sets

\begin{tabular}{cccc}
\hline Method & Reactants & $\Delta \mathrm{E}_{\mathrm{TS}}$ & $\Delta \mathrm{E}_{\text {Product }}$ \\
\hline B3LYP/6-31G** & 0.00 & 40.24 & -35.22 \\
B3LYP/cc-pVDZ & 0.00 & 40.10 & -33.80 \\
B3LYP/6-311++G** & 0.00 & 40.82 & -34.11 \\
B3LYP/AUG-cc-pVTZ & 0.00 & 40.47 & -33.72 \\
MP2/6-31G** & 0.00 & 47.87 & -36.09 \\
MP2/cc-pVDZ & 0.00 & 45.02 & -35.66 \\
${ }^{a}$ QCISD/6-31G** & 0.00 & 48.21 & -35.97 \\
${ }^{a}$ QCISD(T)/6-31G** & 0.00 & 45.53 & -36.20 \\
${ }^{a}$ MP4D/6-31G** & 0.00 & 49.42 & -36.05 \\
${ }^{a}$ CCSD/6-31G** & 0.00 & 48.87 & -35.91 \\
${ }^{a}$ CCSD(T)/6-31G** & 0.00 & 45.76 & -36.18 \\
\hline
\end{tabular}

${ }^{a}$ Single point calculations on the B $3 L Y P / 6-31 G^{* *}$ structures

One can notice that the barriers obtained at B3LYP levels for different basis sets are comparable. The four-centered transition state in both the cases is found to be around $40.00 \mathrm{kcal} / \mathrm{mol}$ at the B3LYP/6-31G** level. The MP2 values for the barrier are somewhat higher. The higher level $a b$ initio calculations also give higher values but inclusion of triples is seen to give significantly lower barriers both in the quadratic configuration interaction (CI) and coupled cluster (CC) scheme. As the B3LYP barrier for this case are only moderately higher than for the approach along the plane discussed in the previous section, are expects that both mechanisms are viable with the approach along the plane being preferred somewhat over the perpendicular approach.

\section{Concluding remarks}

In summary, we have investigated the stationary structures involved in the hydroalumination of cyclopropane with borane. Our study posits a four-centered transition state for this reaction in contrast to the recent studies on the hydroboration of cyclopropane, in which three-centered transition state has been reported. It is also hoped that studies on reactions involving cyclopropane and its derivatives with other hydroalumination reagents will clarify the situation. 


\section{Acknowledgment}

One of the authors (S.P.S.) is grateful to the Ministry of Human resources and Development (MHRD), Government of India for the award of a fellowship.

\section{References}

1. $\quad$ Aldridge S and Downs A J, Chem Rev., 2001, 101(11), 3305-3366.

2. Rao B K, Jena P, Burkart S, Ganteför G and Seifert G, Phys Rev Lett., 2001, 86(4), 692-695.

3. Gámez J A, Guillemin J C, Otilia M and Manuel Y, Chem - A Eur J., 2008, 14(7), 2201-2208.

4. Greenwood N N, Chem Soc Rev., 1992, 21(1), 49-57.

5. Lipscomb W N, Science, 1977, 196(4294), 1047-1055.

6. Carey A and Sundberg R J, Advanced Organic Chemistry: Structure and Mechanisms, Springer: New York, 2000.

7. Zweifel G and Miller J A, Org React., 1984, 32, 375.

8. Winterfeldt E, Synthesis, 1975, 1975(10), 617-630.

9. $\quad$ Marek J and Normant J F, Chem Rev., 1996, 96(8), 3241-3268.

10. Eisch J J, Comprehensive Organic Synthesis, In: Brewster J H, (Ed.), Pergamon, Oxford, 1991, 8, 733.

11. Zweifel G, Aspects of Mechanism and Organometallic Chemistry, In: Brewster J H, (Ed.), New York: Plenum Press, 1978,

12. Zweifel G, Comprehensive Organic Chemistry, In: Barton D H R and Ollis W D, (Eds.), Oxford: Pergamon, 1979, 1013.

13. Negishi E, Organometallics in Organic Synthesis, New York: Wiley, 1980.

14. Saito S, In: Main Group Metals in Organic Synthesis, Yamamoto H and Oshima K, (Eds.), Weinheim: Wiley-VCH, 2004, 189.

15. Miller J A, In : Chemistry of Aluminum, Gallium, Indium and Thallium, Downs A J, (Ed)., London: Blackie Academic, 1993, 372-429.

16. Bundens J W and Francl M M, Organomet., 1993. 12(5), 1608-1615.

17. Egger K W, J Am Chem Soc., 1969, 91(11), 2867-2871.

18. Eisch J J, Comprehensive Organometallic Chemistry, In: Wilkinson G, Stone F G A and Abel E W, (Eds)., Chapter 6, Oxford, U.K.: Pergamon, 1982.

19. Gropen O and Haaland A, Acta Chem Scand Ser A, 1981, 35, 305.

20. Gropen O and Haaland A, Acta Chem Scand Ser A, 1982, 36, 435.

21. Sakai S, J Phys Chem., 1991, 95(1), 175-178._DOI: 10.1021/j100154a035

22. Higashi G S; Raghavachari K and Steigerwald M L, J Vac Sci Tech B: 1990, 8(1), 103-105. DOI: $10.1116 / 1.584853$

23. Dahlmann $\mathbf{M}$ and Lautens $\mathbf{M}$, Metal-Catalysed Hydroalumination Reactions, In: Togni A and Grüzmacher H, (Eds.), Wiley-VCH Verlag GmbH, 2001, 47. DOI: $10.1002 / 3527600159 . c h 2$

24. Evgeniy Yu Pankratyev, Tatyana V Tyumkina, Lyudmila V Parfenova, Leonard M Khalilov, Sergey L Khursan and Usein M. Dzhemilev, Organomet., 2009, 28(4), 968-977.

25. Houk K N, Nelson G. Rondan, Yun-Dong Wu, James T Metz and Michael N PaddonRow, Tetrahedron, 1984, 40(12), 2257-2274.

26. Wang X, Li Y, Wu Y-D, Paddon-Row M N, Rondan N G and Houk K N, J Org Chem., 1990, 55(9), 2601-2609.

27. Nagase S, Ray N K and Morokuma K, J Am Chem Soc., 1980, 102(13), 4536-4537. 
28. Van Eikema Hommes N J R and Schleyer P V R, J Org Chem., 1991, 56(12), 4074-4076.

29. Chey J, Choe H S, Chook Y M, Jensen E, Seida P R and Francl M M et al., Organometallics., 1990, 9(9), 2430-2436.

30. Bundens J W, Yudenfreund J and Francl M M, Organometallics., 1999, 18(19), 3913-3920.

31. Singh S P and Thankachan P P, J Mol Model., 2012, 18(2), 751-754.

32. Frisch M J et al., Gaussian 98, Revision A.7; Gaussian, Inc.: Pittsburgh, PA., 1998.

33. Becke A D, J Chem Phys., 1993, 98, 5648-5652.

34. Gordon M S, J Am Chem Soc., 1980, 102(25), 7419-7422.

35. Ditchfield R, Hehre W J and Pople J A, J Chem Phys., 1971, 54(2), 724-728.

36. Hehre W J; Ditchfield R and Pople J A, J Chem Phys., 1972, 56(5), 2257-2261.

37. Hariharan P C and Pople J A, Mol Phys: An International Journal at the Interface Between Chemistry and Physics, 1974, 27(1), 209-214.

37. Hariharan P C and Pople J A, Theoretical Chemistry Accounts: Theory, Computation and Modeling (Theoretica Chimica Acta), 1973, 28(3), 213-222.

38. Clark T, Jayaraman Chandrasekhar, Günther W. Spitznagel and Paul Von Ragué Schleyer, J Comp Chem., 1983. 4(3), 294-301.

39. Frisch M J, Pople J A and Binkley J S, J Chem Phys., 1984, 80(7), 3265-3269.

40. Woon D E and Jr Dunning T H, J Chem Phys., 1993, 98(2), 1358-1371.

41. Kendall R A, Jr Dunning T H and Harrison R J, J Chem Phys., 1992, 96(9), 6796-6806.

42. Dunning J T H, J Chem Phys., 1989, 90(2), 1007-1023.

43. Peterson K A, Woon D E and Jr Dunning T H, J Chem Phys., 1994, 100(10), 7410-7415.

44. Wilson A K, van Mourik T and Jr Dunning T H, J Mol Struct (THEOCHEM), 1996, 388, 339-349.

45. Head-Gordon M, Pople J A and Frisch M J, Chem Phys lett., 1988, 153(6), 503-506.

46. Frisch M J Head-Gordon M and Pople J A, Chem Phys lett., 1990, 166(3), 275-280.

47. Frisch M J, Head-Gordon M and Pople J A, Chem Phys lett., 1990, 166(3), 281-289.

48. Head-Gordon M and Head-Gordon T, Chem Phys lett., 1994, 220(1-2), 122-128.

49. Sæbø S and Almlöf J, Chem Phys lett., 1989, 154(1), 83-89.

50. Cizek J, Adv Chem Phys., 1969, 14, 35.

51. Purvis Iii G D and Bartlett R J, J Chem Phys., 1982, 76(4), 1910-1918.

52. Scuseria G E, Janssen C L and Schaefer Iii H F, J Chem Phys., 1988, 89(12), 7382-7387.

53. Scuseria G E and Schaefer Iii H F, J Chem Phys., 1989, 90(7), 3700-3703.

54. Pople J A and Gordon M, J Am Chem Soc., 1967, 89(17), 4253-4261. 